\title{
Ultrasound in chronic liver disease
}

\author{
J. F. Gerstenmaier • R. N. Gibson
}

Received: 5 March 2014 /Revised: 16 April 2014 / Accepted: 17 April 2014 / Published online: 24 May 2014

(C) The Author(s) 2014. This article is published with open access at Springerlink.com

\begin{abstract}
Background With the high prevalence of diffuse liver disease there is a strong clinical need for noninvasive detection and grading of fibrosis and steatosis as well as detection of complications.

Methods B-mode ultrasound supplemented by portal system Doppler and contrast-enhanced ultrasound are the principal techniques in the assessment of liver parenchyma and portal venous hypertension and in hepatocellular carcinoma surveillance.

Results Fibrosis can be detected and staged with reasonable accuracy using Transient Elastography and Acoustic Radiation Force Imaging. Newer elastography techniques are emerging that are undergoing validation and may further improve accuracy. Ultrasound grading of hepatic steatosis currently is predominantly qualitative.

Conclusion A summary of methods including B-mode, Doppler, contrast-enhanced ultrasound and various elastography techniques, and their current performance in assessing the liver, is provided.

Teaching Points

- Diffuse liver disease is becoming more prevalent and there is a strong clinical need for noninvasive detection.

- Portal hypertension can be best diagnosed by demonstrating portosystemic collateral venous flow.

- B-mode US is the principal US technique supplemented by portal system Doppler.

- B-mode US is relied upon in HCC surveillance, and CEUS is useful in the evaluation of possible HCC.
\end{abstract}

J. F. Gerstenmaier $(\bowtie) \cdot$ R. N. Gibson

Department of Radiology, (RNG also University of Melbourne) The

Royal Melbourne Hospital, Grattan Street, Parkville, VIC 3050,

Australia

e-mail: jan.gerstenmaier@mh.org.au

R. N. Gibson

e-mail: robert.gibson@mh.org.au
- Fibrosis can be detected and staged with reasonable accuracy using TE and ARFI.

- US detection of steatosis is currently reasonably accurate but grading of severity is of limited accuracy.

Keywords Fibrosis · Cirrhosis · Fatty liver disease · Elastography · Ultrasound · Contrast-enhanced ultrasound . Doppler $\cdot$ Hepatocellular carcinoma $\cdot$ Portal venous hypertension

\section{Introduction}

Ultrasound (US) has a major role in the diagnosis and management of chronic liver diseases by providing diagnostic and prognostic information as well as detecting complications such as HCC and portal hypertension. While conventional ultrasound is valuable in the assessment of liver parenchyma and detection of liver lesions, a range of other US techniques has been developed that increases its potential value. Noninvasive methods of measurements in chronic liver disease are rapidly changing in performance capabilities and availability. These include laboratory tests and imaging studies. An area of intense recent interest has been elastography because of its ability to provide noninvasive information about the stage of liver fibrosis.

The purpose of this review is to summarise the range of US techniques now available and to provide some perspective on their current and potential future value, with a particular focus on elastography, one of the techniques now in mainstream use.

\section{The clinical challenge- fibrosis and steatosis detection and grading}

Hepatic fibrosis is a response to chronic liver injury and a process that tends to progress to cirrhosis and end-stage liver 
disease. While alcohol and infection with hepatitis $\mathrm{B}$ virus (HBV) and hepatitis $\mathrm{C}$ virus (HCV) are still the leading causes worldwide, the increasing prevalence of metabolic syndrome and obesity has resulted in an increasing incidence of cirrhosis secondary to non-alcoholic fatty liver disease (NAFLD). The prevalence of NAFLD is higher than previously estimated [1]. If the incidences of obesity and diabetes continue to rise at the current rate, the prevalence of NAFLD in the US is expected to exceed $50 \%$ in 2030, reaching epidemic status [2]. Non-alcoholic steatohepatitis (NASH), first described in 1980 [3], is a severe and progressive form of NAFLD and is now recognised as a major cause of cirrhosis.

Most histological staging systems for fibrosis and cirrhosis provide five stages, e.g. the METAVIR [4]: stage 0 $(\mathrm{F} 0)=$ normal connective tissue; stage $1(\mathrm{~F} 1)=$ fibrous portal expansion; stage $2(\mathrm{~F} 2)=$ periportal or scanty porto-portal septa; stage 3 (F3) = fibrous septa with architectural distortion; stage $4(\mathrm{~F} 4)=$ cirrhosis. Stages 2 and 3 are considered significant and severe fibrosis respectively. Staging liver fibrosis is important for several reasons: in chronic viral disease, identification of the severity of the liver damage is necessary in order to allow a timely treatment start to avoid progression to cirrhosis when fibrosis stage 2 or beyond is present; the monitoring for progression or regression of liver fibrosis during treatment; and the commencement of monitoring for complications (HCC, PHT) in fibrosis stage 3 or cirrhosis.

Macrovesicular steatosis of the liver can be graded S0-S3 based on percent of hepatocytes in the biopsy involved ( $\mathrm{S} 0$ is none; $\mathrm{S} 1$ is up to $33 \%$; $\mathrm{S} 2$ is $33-66 \%$; $\mathrm{S} 3$ is $>66 \%$ ) [5]. The grade of steatosis is one parameter in the staging for NASH, e.g. used in the the NASH CRN scoring system [6]. Very similar to the grading system proposed by Brunt et al. is the NASH revised criteria used for histological scoring by Dixon with grades $0-4$ assigned to $<5 \%, 5-25 \% 25-50 \%, 50-75 \%$ and $>75 \%$ respectively [7].

With emerging treatments for hepatic fibrosis and NAFLD there is growing demand for accurate diagnosis, prognosis and monitoring of the disease. Traditionally, liver biopsy has been considered the gold standard in fibrosis assessment $[8,9]$. Liver biopsy has a number of disadvantages. As an invasive test, it has a complication rate of approximately $1 \%$ [10-12]. Liver biopsy has been shown to have a high rate of sampling error in patients with diffuse parenchymal liver diseases. A typical specimen volume taken at core biopsy represents only 1/50,000 of liver volume [13]; however fibrosis is heterogeneously distributed in the liver. As an example, in a series of $124 \mathrm{HCV}$ patients, samples taken from the right and left hepatic lobes differed in histological grading and staging. As a result of sampling error, underdiagnosis of cirrhosis occurred in $14.5 \%$ of the patients [14].

\section{Ultrasound modalities}

B-mode ultrasound

\section{Fatty liver disease}

At conventional B-mode ultrasound, diffuse fatty infiltration results in increased echogenicity of the liver when compared to other organs such as the renal cortex (Fig. 1). Features include increased echogenicity of the liver parenchyma, poor or non-visualisation of the diaphragm, intrahepatic vessels and posterior part of the right hepatic lobe. Qualitative grading is conveniently made as mild, moderate or severe, or grade $0-3$ with 0 being normal. Grade 1 (mild) is represented by a diffuse slight increase in fine echoes in the hepatic parenchyma with normal visualisation of the diaphragm and intrahepatic vessel borders. Grade 2 (moderate) is represented by a moderate diffuse increase in fine echoes with slightly impaired visualisation of the intrahepatic vessels and diaphragm. Grade 3 (marked) is represented by a marked increase in fine echoes with poor or no visualisation of the intrahepatic vessel borders, diaphragm and posterior portion of the right lobe of the liver [15]. Focal fatty sparing may be seen in grades 2 and 3. A de facto validation of qualitative grading has occurred in a meta-analysis that included data from studies comparing US with histopathological findings. Ultrasound was found to have acceptable diagnostic accuracy for detecting moderate or severe hepatic steatosis in adults, with pooled sensitivities ranging from 0.857 to 0.991 and pooled specificities ranging from 0.852 to 0.919 [16]. Cutoff values for grading steatosis varied across studies included in the meta-analysis but were not less than $25 \%$ for moderate to severe hepatic steatosis. The sensitivities and specificities for mild (less than $5 \%$ ) steatosis were 0.733 and 0.844 respectively.

Data in the adolescent population are scarce. In a small series of 34 overweight Egyptian children with liver biopsy,

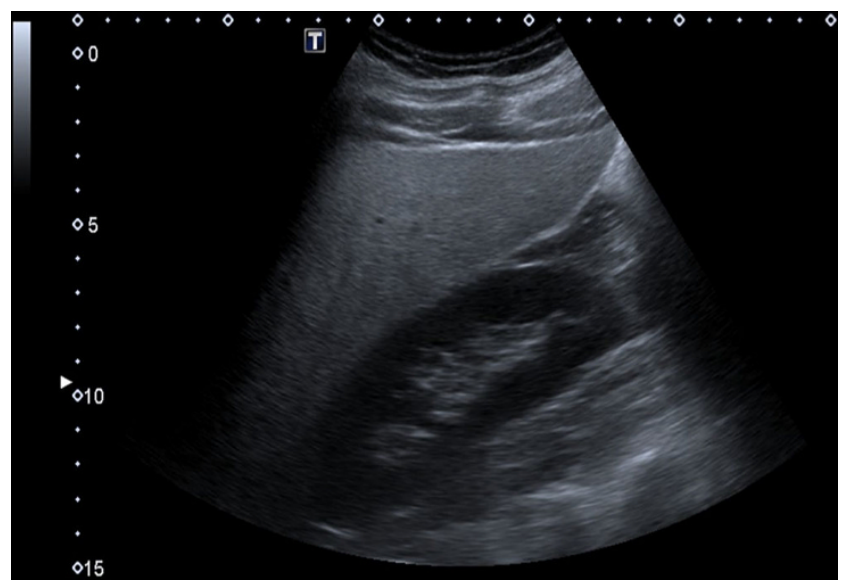

Fig. 1 B-mode ultrasound of liver and right kidney. Diffuse fatty infiltration. The liver is of markedly increased echo intensity relative to the renal cortex, indicative of severe steatosis 
qualitative ultrasound scores of 0 or 1 were found to exclude histological NAFLD [17]. In an earlier prospective study of 104 adolescents, qualitative scores $0-3$ for the presence of fatty infiltration at ultrasound were compared with MR spectroscopy results. While negative US results excluded the presence of severe steatosis with acceptable accuracy, positive US results in severely obese adolescents could not be used to accurately predict the presence and severity of hepatic steatosis [18].

Due to substantial inter- and intraobserver variability [19] and the reduced sensitivity in low levels of steatosis [16, 20], it has been suggested that the effectiveness of steatosis detection can be increased by quantification of liver brightness. The sonographic hepatorenal index (SHRI) is based on comparison between liver and kidney brightness. An image including both liver and kidney is required, typically showing segment 6 of the liver and the upper pole of the right kidney. Regions of interest (ROI) of an appropriate size ( $>400$ pixels) are selected in the liver parenchyma, excluding vessels, and renal cortex at the same field depth. The mean brightness of each ROI is determined using numerical values assigned to grey-scale pixels. Some ultrasound systems allow the placement of ROIs directly on the screen. Alternatively, a suitable image can be exported and ROIs placed using proprietary software or public domain programmes such as ImageJ (National Institutes of Health, Bethesda, MD, USA). The SHRI is the mean liver brightness divided by the mean renal cortex brightness (Fig. 2). Significant correlation between histological steatosis and the SHRI has been found in several studies. In addition, point estimates of SHRI for the prediction of steatosis grades less than moderate or severe appear to be superior to those of qualitative grading methods. In a series of 101 patients who underwent liver biopsy, a strong correlation between the SHRI and percentage of fat was shown (Spearman's coefficient $=$ $0.71, P<0.001$ ) [21]. In this study, liver biopsy was performed for a variety of reasons including elevated liver function tests, $\mathrm{HCV}$, orthotopic liver transplant and HBV. A SHRI cutoff of 1.28 had a sensitivity of 1 and a specificity of 0.54 for the diagnosis of steatosis greater than $5 \%$. The authors reported that more than $1 / 3$ of biopsies could have been avoided in their series of 101 patients if the SHRI method had been used prospectively. In another study of 42 NAFLD patients and 40 healthy controls, the SHRI cutoff for predicting steatosis was 1.24 with a sensitivity of 0.93 and a specificity of 0.93 [22]. In a series of 111 consecutive patients undergoing liver biopsy for a variety of indications including HBV, HBC and abnormal liver enzymes, the SHRIs were determined retrospectively. An SHRI cutoff point of 1.49 had a sensitivity of 1 and specificity of 0.91 for the prediction of steatosis $>5 \%$ [20]. In a recent study involving patients attending general medical centres, SHRI as determined on a standard workstation without additional software showed strong correlation (Spearman's coefficient $=0.89, P<0.001$ ) with $3 \mathrm{~T}$ MR proton spectroscopy as a reference to determine the degree of steatosis [23]. The authors found that SHRI cutoff points of $1.21,1.28$ and 2.15 yielded $100 \%$ sensitivity for the diagnoses of steatosis greater than $5 \%, 25 \%$ and $50 \%$, respectively, with a specificity greater than $70 \%$. The degrees of steatosis referred to in this study correspond to those in the Dixon steatosis grading system [7]. It appears that amongst the limited number of studies to date, no uniformly agreed SHRI threshold for cutoffs of degrees of steatosis have been found.

Regarding reproducibility, repeat measurements of the SHRI in a sample of hospital workers were made several days apart by one sonographer. An $r$ value of 0.77 for correlation between the two measurements was achieved. A kappa value
Fig. 2 Quantification of echo intensity. Principle of the sonographic hepatorenal index. ROIs are placed over the liver parenchyma and renal cortex at the same depth. Mean echo intensities are determined on a standard 8-bit US image, e.g. in this example with freeware ImageJ, National Institutes of Health, Bethesda, MD, USA). SHRI is calculated by dividing the mean liver brightness by the mean renal cortex brightness. In this example $59 / 14=4.21$, i.e. severely fatty [20-23]
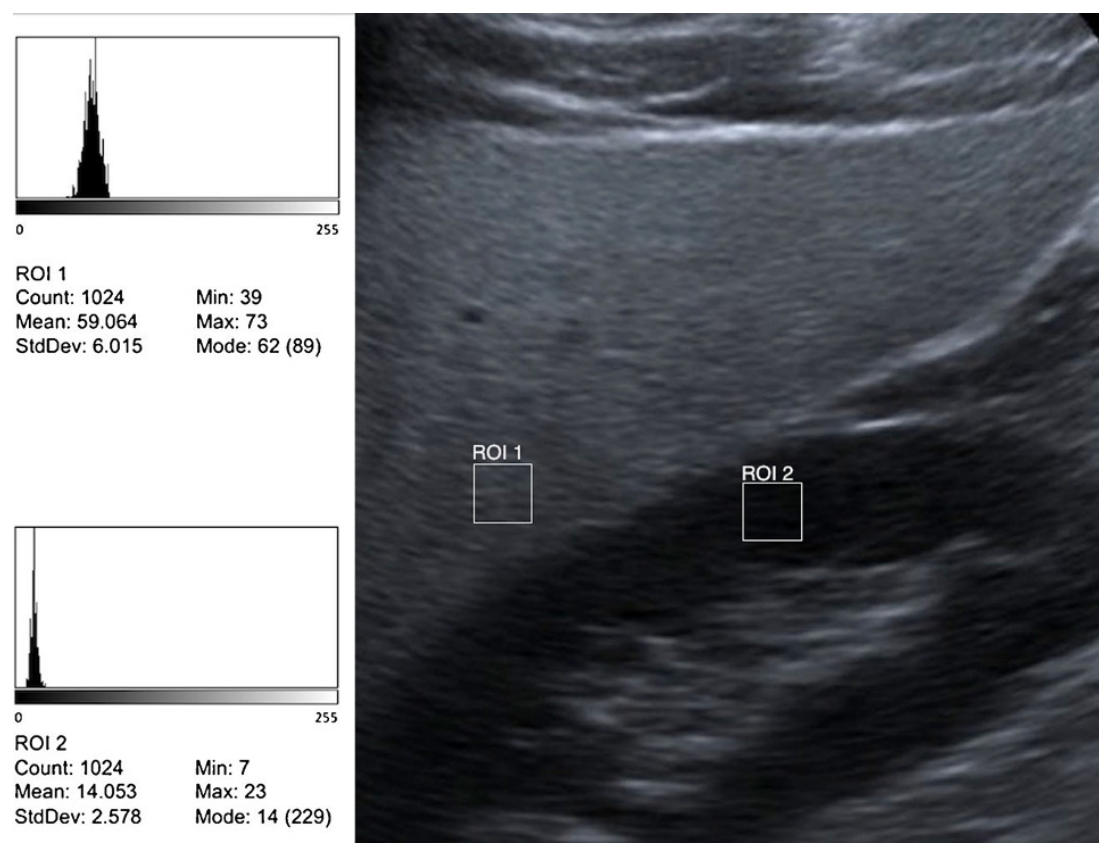
of 0.86 when applying a cutoff point of 1.49 for the diagnosis of steatosis indicates very good intraobserver agreement [20]. Interobserver agreement for the SHRI has not been assessed.

In summary, the SHRI appears to be an appealing technique for diagnosis and quantification of hepatic steatosis. It can be performed without new investment, but a standardised technique and interobserver agreement still need to be determined.

Lee et al. describe a "dark band at the posterior deep portion of the liver" [24] on tissue harmonic compound sonography (Fig. 3). This becomes especially conspicuous when the fundamental mode of compound sonography is converted to the tissue harmonic compound sonography mode for evaluation of focal hepatic lesions. We have also observed this phenomenon. Compound sonography has the advantage of better sharpness and contrast, and an improved signal-to-noise ratio. Especially when combined with tissue harmonic imaging, noise is kept to a minimum and some artefacts such as reverberation are removed, ideal for investigating a focal lesion [25-27]. As a trade-off, posterior shadowing may become more conspicuous. An explanation of the dark area could be an abrupt drop in the harmonic signal in deeper portions due to the effect of fatty infiltration on acoustic penetration. Termed the "fade-out sign", this phenomenon was investigated for its value in diagnosing fatty liver disease [24]. At this time the fade-out signal appears to be an observed qualitative feature of hepatic steatosis at harmonic US imaging.

\section{Echotexture analysis}

A feature of ultrasound is the presence of speckle noise. Within an image, speckle is an intensity pattern formed by the interference of many scatters and not a direct representation of the underlying structure. However, the local brightness

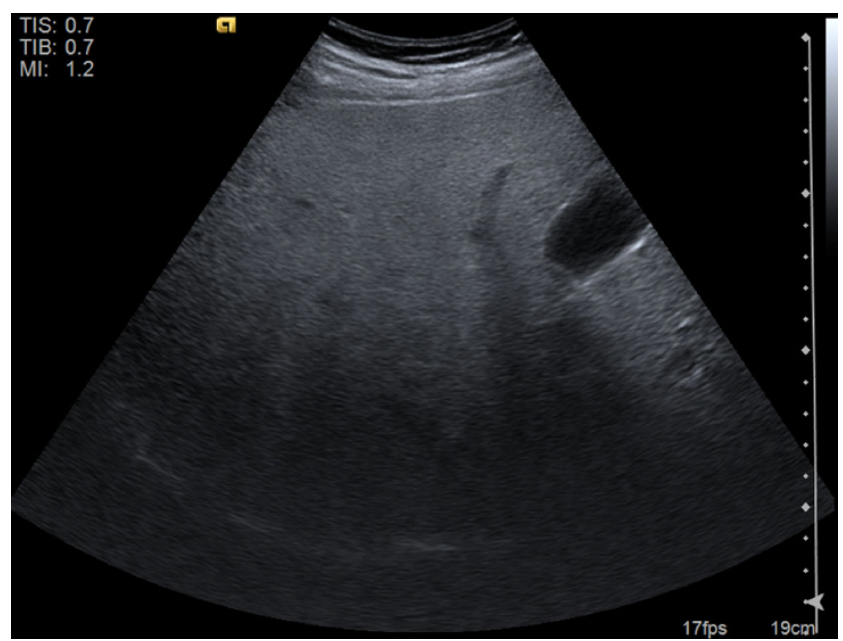

Fig. 3 Tissue harmonic compound sonography. Signal drop in the far field (fade-out sign) indicated severe diffuse fatty infiltration of the speckle reflects the corresponding echogenicity of the underlying scatterers, in the case of liver ultrasound likely the hepatic lobules.

The speckle pattern changes with both steatosis and fibrosis. Microarchitectural changes may be imperceptible to the naked eye on a conventional B-mode image. Acoustic structure quantification (ASQ) is one method of quantifying the statistical deviation of ultrasound signals that occurs in diffuse pathological processes [28]. In the evaluation of fibrosis and cirrhosis, ASQ as yet has not been shown to perform as well as TE [29]. ASQ technology has been proposed for the quantification of steatosis [30]. Figure 4 shows an example of how ASQ is displayed.

\section{Fibrosis and cirrhosis}

Liver parenchymal texture is a characteristic that is somewhat subjective and has low sensitivity for the detection of cirrhosis. A recent retrospective study on the accuracy of conventional US in the staging of fibrosis found that routine US is not an accurate predictor for either early or significant fibrosis in chronic viral hepatitis [31]. However in a series of 103 patients with chronic liver disease it has been shown that liver parenchymal texture (graded as fine echotexture, mildly coarse, coarse and highly coarse) has a statistically significant correlation ( $\mathrm{rs}=0.8853$ ) with the degree of fibrosis [32]. When combined with two more features (liver surface nodularity and liver edge), correlation with the degree of fibrosis increased to $r s=0.9524$. When compared to echotexture, liver surface nodularity (Fig. 5) has better accuracy for the presence of cirrhosis [33-35] reaching both a sensitivity and specificity of 0.88 . In order to provide a fluid-tissue interface, ascites needs to be present for optimal evaluation. Once ascites is present, cirrhosis is generally more advanced and less of a diagnostic challenge.

A different approach is the use of the hepatic vein lumen as an internal fluid-tissue interface when ascites is absent (Fig. 6). Assuming that internal nodularity in cirrhosis would cause architectural distortion, the hepatic vein morphology would also be altered. In a prospective pilot study comprising 38 patients with cirrhosis and 50 patients without liver disease, the following features were evaluated: hepatic vein straightness, uniformity of hepatic vein echogenicity and visualisation of a 1-cm segment of hepatic vein [36]. Hepatic vein straightness, stratified into three categories (straight, slightly wavy and very wavy) yielded the highest sensitivity and specificity of 0.97 and 0.91 respectively using real-time compound imaging (RTCI) with a 5-2 MHz transducer. Uniformity of hepatic vein wall echogenicity was the next useful feature with a sensitivity and specificity of 0.88 and 0.86 respectively, similar to earlier studies on superficial surface nodularity. With all three features combined, specificity for cirrhosis reached 0.98 using RTCI; however sensitivity reduced to 
Fig. 4 Speckle pattern analysis with acoustic structure quantification (ASQ). Upper images: Homogeneous normal liver parenchyma is displayed as green whereas portal tracts and other structures with different and heterogeneous structure are highlighted in red. Lower images: Example of quantitative tools showing the probability density function (green curve) and theoretical speckle generated by Rayleigh distribution (red)

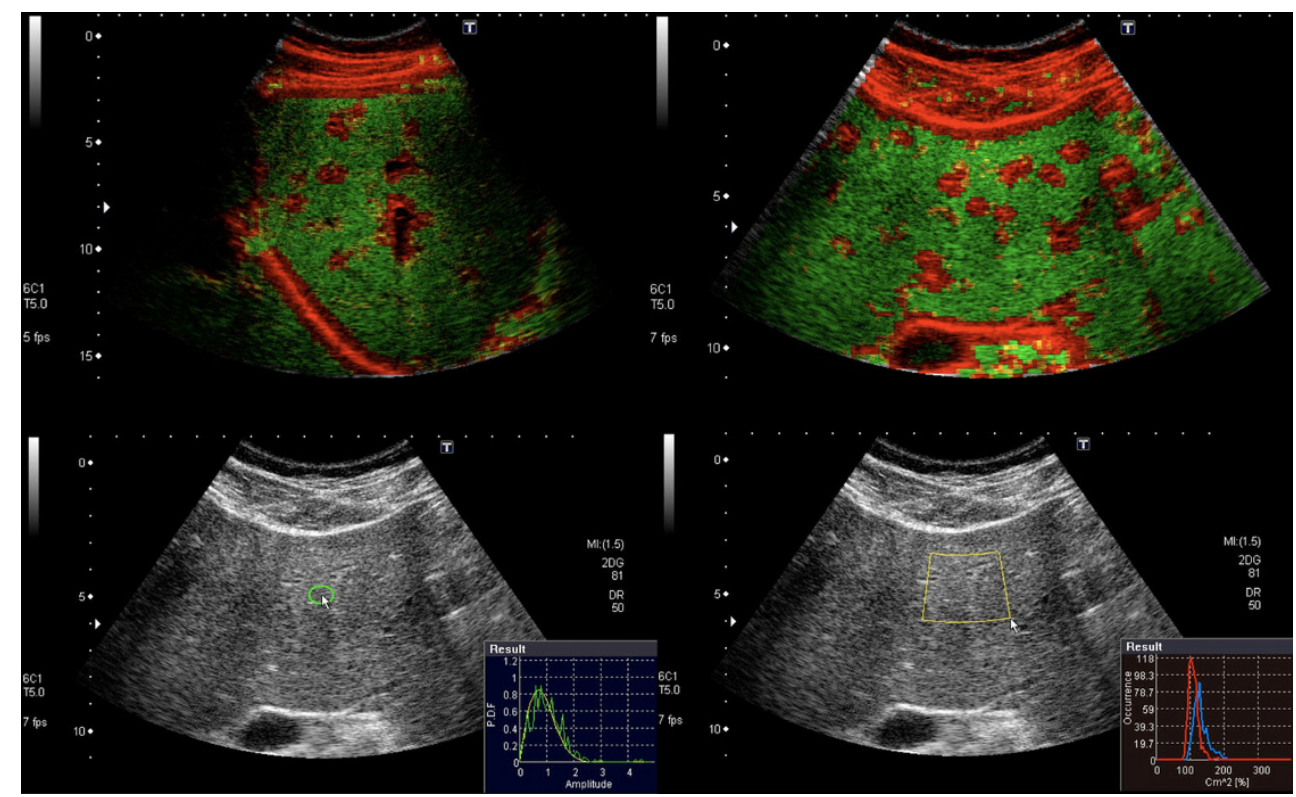

0.65 . In this pilot study, the assessment of the hepatic vein morphology has been shown to be a good indicator of cirrhosis with favourable inter- and intraobserver error. While validation with more rigorous clinicopathological correlation and larger patient numbers is required, the three hepatic vein morphology characteristics can easily be evaluated in clinical practice. The authors now recommend that examination of the hepatic vein wall should preferably be performed in segment 5 or 6. A peripheral tributary should be selected perpendicular to the ultrasound beam in order to achieve a good specular reflection. The peripheral tributary should measure approximately $3 \mathrm{~mm}$ in diameter and at least $15 \mathrm{~mm}$ in length; choosing a peripheral tributary also allows the use of higher resolution scanning [37].

While hepatic vein wall morphology appears to be a feature with excellent accuracy for the diagnosis of cirrhosis in the pilot study [36], a recent study was not able to demonstrate this high sensitivity and reported liver surface nodularity to be

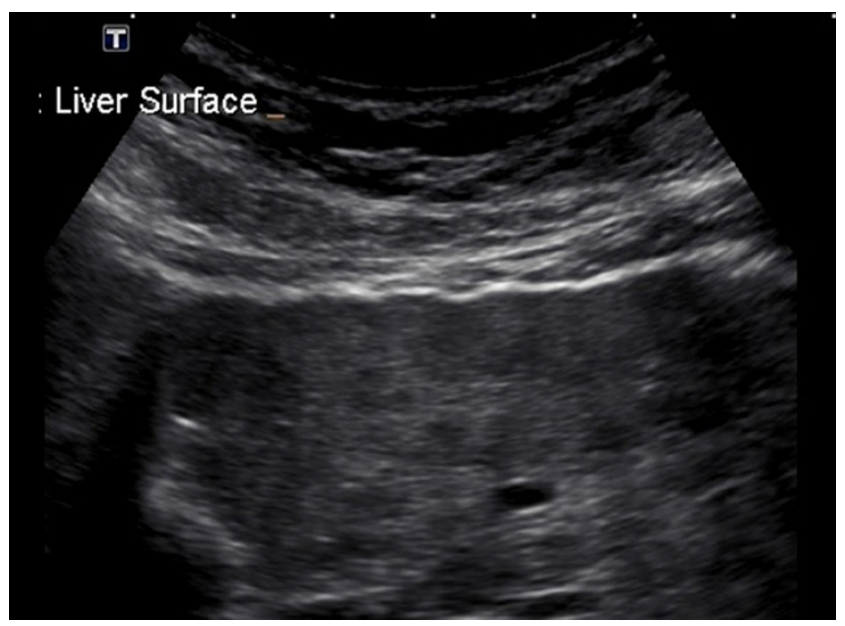

Fig. 5 Example of surface nodularity more sensitive [38]. It is likely that these discrepant findings are technique related. When applying a meticulous technique as detailed in Gibson et al. [37], the authors' experience is that diagnostic confidence is higher with hepatic vein morphology than with surface nodularity.

Portal vein diameter is known to increase following a meal, and the effect can be as much as $50 \%$ [39]. In a small series, this effect has been shown to be present in normal subjects and chronic hepatitis patients alike, but in liver cirrhosis mean calibre, mean flow velocity and mean flow volume remained largely unchanged after a meal [40]. Absolute portal vein calibre has been considered a sign of portal venous hypertension with cutoff values of 13-15 mm [41-43], however with poor sensitivities of $0.13-0.4$. The lack of sensitivity is likely due to the presence of collateral pathways that decompress the system. An angiography-based study concurred with the finding that portal vein diameter did not increase along with the portohepatic gradient in portal venous hypertension [44]. In our experience, the portal vein diameter may even appear small in the setting of hepatofugal flow. In our practice little significance is attached to this parameter as it has low positive predictive value for portal hypertension and a small percent of normals have portal vein diameters $>13 \mathrm{~mm}$. Portal vein diameter should therefore be interpreted with caution as a marker of portal hypertension.

In portal hypertension more relevant than absolute portal vein diameter may be the absence of normal calibre variations with respiration [45] with a reported sensitivity of up to 0.79 . It is clear, however, that there is too much variance in absolute portal vein diameter to be used in the diagnosis of portal venous hypertension. Further, in our experience ultrasound access and compliance with breathing directions are often too poor to obtain reliable and reproducible measurements of portal vein diameter change. 
Fig. 6 Hepatic vein wall morphology. Against contrast of anechoic blood within the hepatic vein, the wall appears wavy, concurring with the known diagnosis of cirrhosis. In the absence of ascites, surface nodularity may not be as conspicuous as in Fig. 5

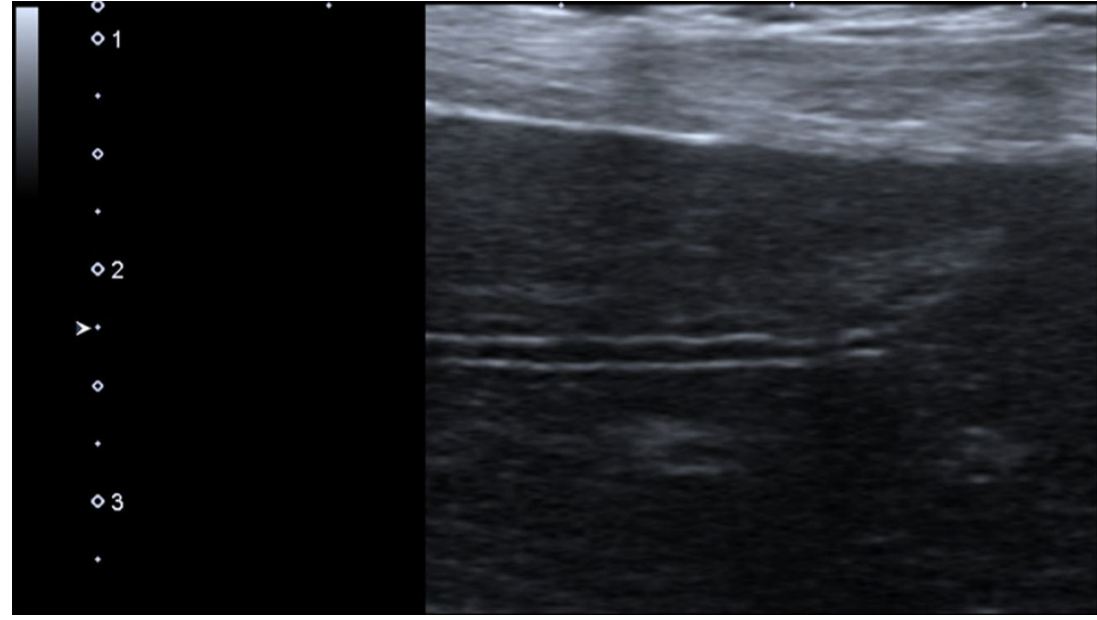

\section{Doppler ultrasound}

Doppler ultrasound can measure hepatic blood flow. In the past, several investigations of the utility of Doppler ultrasound as a noninvasive method of assessing the degree of hepatic fibrosis have been made. The theoretical basis is haemodynamic change in the liver during progression from hepatitis to fibrosis and cirrhosis. Reproducibility of Doppler-derived indices, however, has been poor and correlation between indices and disease stage uncertain. In a well-stratified cohort of 65 patients with biopsy-proven HCV-related liver disease, various hepatic vascular indices were investigated prospectively including the hepatic artery velocity and hepatic artery resistive index, portal vein velocity, portal vein diameter and circumference, portal vein congestive index and hepatic artery-portal vein velocity ratio [46]. In less than half of the patients in this study, reproducible and accurate hepatic artery traces and derived indices could be obtained, and in less than one third of patients an accurate portal vein circumference could be determined. The portal vein velocity could be measured in 62 patients but mean values were near identical for different degrees of hepatitis and cirrhosis. Overall there were no significant differences observed in the Doppler indices with increasing severity of liver disease. The authors conclude that Doppler-derived indices are difficult to reproduce reliably and are therefore of limited clinical value in the assessment of hepatic fibrosis or inflammation.

Hepatic vein waveforms have been used to predict cirrhosis with a tendency for the waveform to be biphasic or monophasic in cirrhosis compared with triphasic in normals. Recently, hepatic vein waveforms were re-evaluated in a series of 120 patients with cirrhosis with a broad range of causes. Flat waveforms occurred in only $3 \%$ of cases; otherwise waveforms were bi- and triphasic. There was no correlation between liver dysfunction and the pattern of hepatic vein waveforms [47]. Variability in venous waveforms is commonly found in clinical practice.
The main role of Doppler ultrasound is the assessment of portal venous hypertension as a complication of cirrhosis. Doppler ultrasound of the ligamentum teres (Fig. 7) showing hepatofugal venous signal (i.e. a patent paraumbilical vein) and hepatofugal flow in the portal vein are both specific signs and have a high positive predictive value for the presence of portal hypertension [48, 49].

Portal vein velocity as a marker of portal hypertension was assessed in a study of 118 patients and found to be highly variable, ranging between 7 and $83 \mathrm{~cm} / \mathrm{s}$. Only $2.6 \%$ of patients in this series had velocities $\leq 10 \mathrm{~cm} / \mathrm{s}$ (a threshold suggested by Zoli [50]), and $6.1 \%$ had velocities $\leq 11 \mathrm{~cm} / \mathrm{s}$ [49]. Low portal vein velocity is therefore not a very useful sign of portal hypertension. The ratio of cross-sectional portal vein diameter and portal vein velocity, termed the 'congestion index' [51], has been proposed as a marker of portal hypertension based on the tendency for portal vein diameter to increase and velocity to decrease. As an index it is not widely used partly because measurement of both parameters of the index is highly variable [49].

Portal venous flow pattern assessment is also valuable in the diagnosis of portal hypertension. Normal portal venous flow is continuous and hepatopetal on Doppler ultrasound with minimal variations due to the cardiac cycle and respiration. Reversed (hepatofugal) portal venous blood flow can be present when the intrahepatic resistance is greater than the resistance of portosystemic collaterals. Continuous hepatofugal flow is present in $8.3 \%$ of patients with cirrhosis [52] and associated with portosystemic shunts [53].

The significance of left gastric vein diameter is unclear. While some correlation with variceal bleeding has been found [54], others found that dilation of the left gastric vein is not necessary for variceal haemorrhage to occur [55].

In a more recent study, a left gastric vein diameter of more than $6 \mathrm{~mm}$ was found in $58 \%$ of patients with recent variceal bleed and $12 \%$ of patients without a recent variceal bleed; however this difference was not statistically significant [56]. 
Fig. 7 Recanalisation of the paraumbilical vein as shown by venous Doppler signal in the ligamentum teres. This is sensitive and specific for the presence of portal venous hypertension

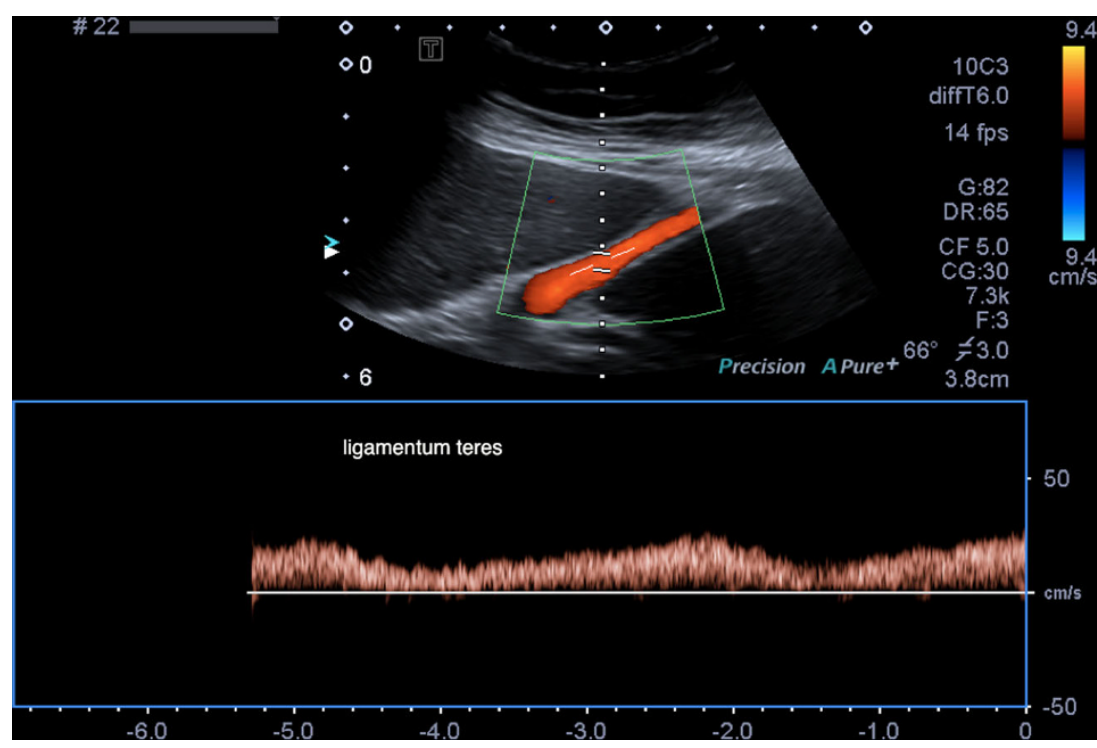

Contrast-enhanced ultrasound

Contrast-enhanced ultrasound (CEUS) uses microbubbles as kinetic tracers. CEUS agents have shown to have a good safety profile with a low incidence of side effects. The safety of SonoVue ${ }^{\circledR}$ (Bracco S.p.A., Milan, Italy) has been shown in a retrospective study of 23,188 where only two serious adverse events and no deaths occurred [57]. They are either blood pool agents or combined blood pool and Kupffer phase agents. Different agents have differing properties and they cannot be used interchangeably.

\section{CEUS in diffuse liver disease}

By measuring vascular transit times and parenchymal enhancement, the severity of liver disease can be assessed. In patients with cirrhosis, the transit times of microbubbles are shortened [58-60]. In addition, it has been shown that using hepatic vein transit times (HVTT) mild hepatitis can be differentiated from moderate and severe hepatitis as well as cirrhosis in HCVrelated liver disease [61]. As HVTT shortens with more disease, this method has been suggested as a marker of response to antiviral treatment in HCV [62]. Different agents behave differently, e.g. hepatic vein transit time has been shown to be significantly shorter with SonoVue than with the then available blood pool agent Levovist ${ }^{\circledR}$ (Schering AG, Berlin, Germany) [63]. While the diagnostic accuracy of transit times appears good, the technique is complex and exacting with questionable reproducibility, and the technique is not in mainstream use.

It has been shown that the behaviour of intrahepatic microbubbles depends on the severity of hepatic fibrosis. Sonazoid ${ }^{\mathrm{TM}}$ (GE Healthcare, Oslo, Norway), using perfluorobutane as its gas core, is captured in reticuloendothelial tissue. Using this agent in a prospective study of 202 subjects, intrahepatic accumulated microbubbles were used to predict the grade of liver fibrosis [64]. There was significant correlation between the intensity difference and the fibrosis grade. The sensitivity, specificity and efficiency of the intensity difference were $0.88,0.72$ and 0.81 for marked fibrosis, $0.85,0.91$ and 0.89 for advanced fibrosis and 0.97, 0.9 and 0.91 for cirrhosis respectively. Until recently, the CEUS agent Sonazoid ${ }^{\mathrm{TM}}$ was only available in Japan.

\section{CEUS for lesion characterisation in the setting of chronic liver disease}

CEUS can be used in the diagnosis and management of hepatocellular carcinoma, an end point of cirrhosis. The typical features of arterial hyperenhancement and washout as seen on $\mathrm{CT}$ or MR can be shown in real time during CEUS. A new concept is defect reperfusion imaging [65] where a Kupffer phase agent such as Sonazoid ${ }^{\mathrm{TM}}$ is injected first. This facilitates lesion detection as pathology deficient of Kupffer cells will stand out as an echopoor defect. With a second injection, these defects can then be assessed for arterial enhancement.

\section{Elastography}

There is a correlation between hepatic parenchymal pathology and liver stiffness. As a surrogate marker of fibrosis and cirrhosis, the measurement of liver stiffness forms the basis of elastography. Stiffness, or the rigidity of an object, is the extent to which it resists deformation in response to a force applied. Elasticity is the tendency of solid materials to return to their original shape after being deformed by a force applied and removed. In elastography, such force is coupled with a system that measures the deformities caused by the force. Ultrasound elastography techniques include transient elastography (FibroScan ${ }^{\circledR}$ ), acoustic radiation force impulse imaging (ARFI), shear wave mode elastography and strain 
elastography. A recent review by Frulio and Trillaud provides details on different elastography techniques as well as a brief discussion on the main serum markers to assess for fibrosis [66]. A 2013 review by the Japan Society of Ultrasonics in Medicine discussed fundamental principles of elastography methods and physics of tissue elastic properties [67].

\section{Transient elastography}

This ultrasound method is based on Hooke's law, which states that the force required to compress or extend a spring is proportional to the distance compressed or extended. This law can be applied to a variety of materials including liver tissue. Transient elastography (TE) is the technique used with the FibroScan ${ }^{\circledR}$ ultrasound unit (Echosens S.A.S.U., Paris/ France). In practice, FibroScan ${ }^{\circledR}$ uses a $5 \mathrm{MHz}$ ultrasound transducer mounted on the axis of a vibrator, placed in a right intercostal space with the patient lying supine and the right arm in maximal abduction. A $50-\mathrm{Hz}$ vibration with an amplitude of $2 \mathrm{~mm}$ created propagates into the liver as elastic shear waves. The speed of wave propagation is proportional to the tissue stiffness and is measured by pulse-echo ultrasound. This measured speed is then converted to the Young modulus using a simplified equation and expressed in kiloPascals ( $\mathrm{kPa})$ [68]. Ten successful measurements are to be obtained in any given patient and the median value in $\mathrm{kPa}$ is calculated (Fig. 8). The stiffer the tissue is, the higher the speed of wave progression.

There are a number of limitations in TE. The major disadvantage in comparison with other elastography techniques is that no ultrasonographic visualisation of the location of the measurement is possible. It is impossible to perform in patients with ascites. The liver stiffness measurements may be influenced by acute liver injury [69-71] indicated by acute aminotransferase flares, extrahepatic cholestasis [72], central venous pressure [73], beta-blockers [74] and food intake [75]. TE is difficult to perform in obese patients or those with a narrow intercostal space. In addition, it is operator dependant. In an analysis of 13,369 cases, a $15.8 \%$ rate of unreliable and $3.1 \%$ rate of failed TE measurements were reported [76]. This corresponds to liver stiffness measurements using TE being uninterpretable in nearly one in five cases. The main reasons were found to be obesity and limited operator experience. In addition, patient age $>52$ years and presence of type 2 diabetes mellitus were independently associated with measurement failure and female gender and arterial hypertension were independently associated with unreliable LS measurements. In order to mitigate the high rate of unreliable measurements in obese patients, a lower frequency $(2.5 \mathrm{MHz}) \mathrm{XL}$ probe has been developed that has achieved reliable measurements in $61 \%$ of obese patients in whom measurements were unreliable using the conventional $\mathrm{M}$ probe [77]. The use of an XL probe in obese patients increased the rate of reliable measurements from less than $50 \%$ (M probe) to approximately $75 \%$.
Similarly for patients with smaller build and children, an S probe with a higher frequency and shallower sampling depth is being developed [78].

The diagnostic performance of TE has been assessed for a variety of aetiologies: HCV [79], HIV/HCV [80, 81], HBV [82], NAFLD [83] and alcoholic liver disease [84]. In a metaanalysis including 40 studies an overall sensitivity and specificity of 0.79 and 0.78 for $F=2$ stage and 0.83 and 0.89 for cirrhosis were reported [85].

In a meta-analysis comprising 18 studies including 2,772 patients exclusively with $\mathrm{HBV}$, the mean area under the ROC curve for the diagnosis of $F=2$ was 0.859 , for $F=30.887$ and for $F=40.929$. The estimated cutoff for $F=2$ was 7.9 (range, 6.1$11.8) \mathrm{kPa}$, with a sensitivity of $74.3 \%$ and specificity of $78.3 \%$. For $F=3$, the cutoff value was determined to be 8.8 (range, 8.19.7) $\mathrm{kPa}$, with a sensitivity of $74.0 \%$ and specificity of $63.8 \%$. The cutoff value for $F=4$ was 11.7 (range, $7.3-17.5$ ) $\mathrm{kPa}$, with a sensitivity of $84.6 \%$ and specificity of $81.5 \%$ [86].

The optimal cutoff values for advanced fibrosis and cirrhosis differ according to aetiology and are subject to debate as even within one aetiology a broad range of cutoff values exist.

In addition to using TE in the assessment of fibrosis and cirrhosis, a new method has emerged for the quantification of steatosis. The amplitude of ultrasound waves decreases as they propagate through the liver. This attenuation is measured using the Fibroscan $\mathrm{M}$ probe and termed the controlled attenuation parameter (CAPTM). Initially assessed in a pilot study of 115 patients, CAPTM detected $>10 \%$ (S1), $>33 \%$ (S2) and $>67 \%$ (S3) steatosis with areas under the ROC curves of 0.91 , 0.95 and 0.89 respectively. The presence of fibrosis did not affect the CAPTM values [87]. Similar performances were found in further studies, e.g. with areas under the ROC curves of $0.84,0.86$ and 0.93 for $>10 \%$ (S1), $>33 \%$ (S2) and $>67 \%$ (S3) steatosis respectively [88] or with areas under the ROC curves of $0.79,0.76$ and 0.70 for $>5 \%,>33 \%$ and $>67 \%$ steatosis respectively [89]. There is evidence that the aetiology of steatosis does not affect the accuracy of CAPTM [90].

The grades of steatosis used in the above studies correspond to the original proposal for grading by Brant et al. [5] with the exception of S1 where the degree of steatosis is $<33 \%$.

Early studies of CAPTM have shown promising results for quantification of hepatic steatosis, although some have reported limited accuracy in the range of severe disease and high failure rates. In a large prospective study of 5323 CAPTM examinations the overall failure rate was $7.7 \%$, and $33 \%$ in elderly females with diabetes and hypertension [91]. Further studies are required for validation and refinement of its use.

In summary, TE is the longest established and most validated technology. It has excellent diagnostic accuracy for cirrhosis and good accuracy for the detection of early cirrhosis. It is user friendly and has a high patient acceptance. There are a number of limitations and pitfalls, and dedicated nonimaging ultrasound hardware is required. The main limitations 
are high BMI and ascites, and there is a variable but not insignificant failure rate.

\section{Acoustic force radiation impulse}

Acoustic Force Radiation Impulse (ARFI) technology is a technique that has been incorporated into an imaging ultrasound unit. A $5 \mathrm{~mm} \times 10 \mathrm{~mm}$ region of interest (ROI) cursor is placed during real-time B-mode scanning. The technique was termed shear wave elastography at a point (pSWE) given the small size of the ROI cursor [68].

The tissue in the ROI is excited with a short duration (262 $\mu \mathrm{s})$ fixed frequency $(2.67 \mathrm{MHz})$ ultrasound pulse to displace tissue locally. The resultant shear wave propagates laterally with a velocity that is proportional to the square root of tissue elasticity and detected with ultrasound-based correlation methods. The speed of the shear wave is measured directly in meters per second and is displayed on the screen (Figs. 9). Unlike TE, ARFI is not impeded by mild to moderate perihepatic ascites. As the technology is implemented in an ultrasound machine, it can be part of any B-mode liver ultrasound scan without switch of equipment (e.g. Virtual Touch ${ }^{\mathrm{TM}}$ Tissue quantification in Siemens ACUSON S2000, Siemens Medical Solution, Erlangen, Germany; Elasto Q Philips iU22, Philips, Best, The Netherlands). In addition, the site of sampling is selectable and known precisely. In practice, ARFI is often carried out as part of liver ultrasound. Segments V/VI or VII/VIII are most suited for sampling, with the left liver lobe best avoided [68, 92, 93]. The two main reasons for better suitability of the right liver for ARFI sampling are the disruption of shear waves by excessive tissue motion secondary to cardiac pulsation affecting the left lobe, and readings in segments II/III are likely to be taken from tissue closer to the capsule, an area known to be more fibrous than deeper zones.

The success rate (SR) has been measured by the ratio of successful acquisitions over the total number of acquisitions and interquartile range (IQR) interval, defined as the difference between the 75 th and the 25 th percentile. These are

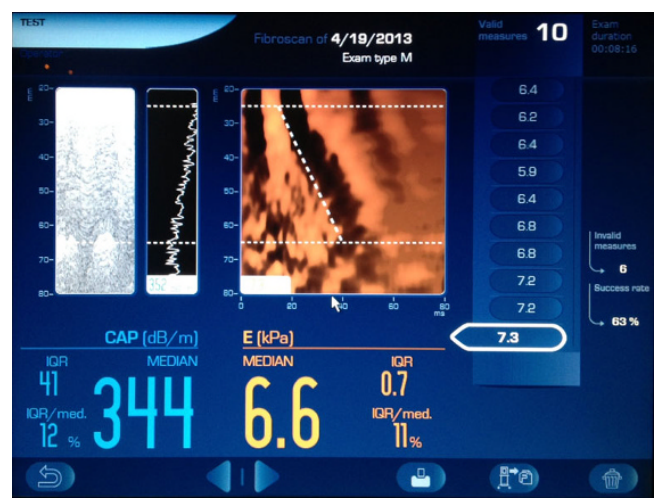

Fig. 8 User interface of Fibroscan. Example of liver stiffness measurement: mean $6.6 \mathrm{kPa}$ falls in the F0 or F1 category (absent or mild fibrosis)

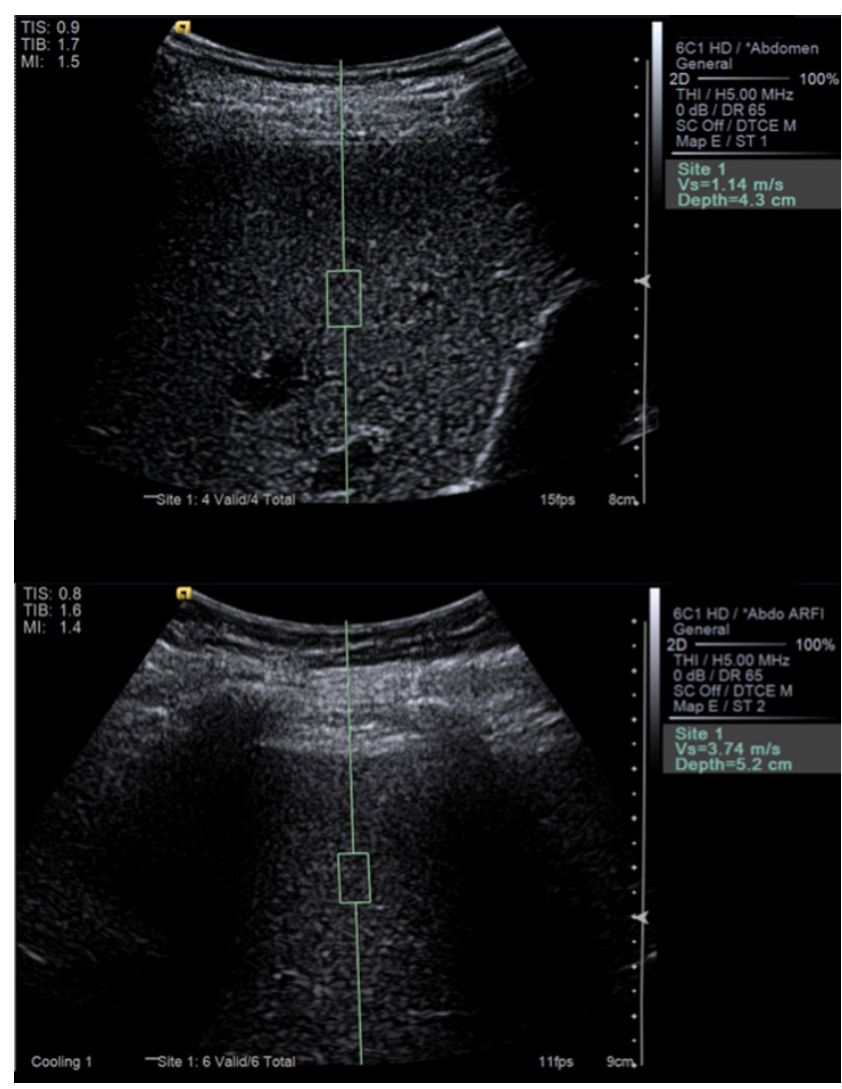

Fig. 9 Elastography (ARFI). Example of normal liver with ARFI value $\mathrm{Vs}=1.14 \mathrm{~m} / \mathrm{s}$ indicating absent or mild fibrosis (F0 or F1), and example of abnormal liver with ARFI value $\mathrm{Vs}=3.74 \mathrm{~m} / \mathrm{s}$ indicating $\mathrm{F} 4=$ cirrhosis

quality technical parameters that have not been recommended by the manufacturer (Siemens); however it has been shown that these values (IQR $<30 \%$ of the median velocity and a $\mathrm{SR} \geq 60 \%$ ) can be used to improve the value of ARFI [94].

Significant inter-observer correlation between ARFI measurements with $r=0.874$ has been shown [93]. In addition, in a later study the intra-operator (intra-class correlation coefficient ICC $=0.9$ ) and inter-operator $(\mathrm{ICC}=0.81)$ reproducibility of ARFI was shown to be good [95] in a study consisting of patients with cirrhosis and fibrosis of various aetiologies and healthy volunteers alike.

ARFI was first used and validated in patients with chronic $\mathrm{HCV}$. In an early pilot study with 86 patients with HCV, the area under the ROC curve for the diagnosis of $F \geq 2$ was 0.82 and for the diagnosis of $F=4$ was 0.91 [96]. In a study of 274 patients with $\mathrm{HCV}$ areas under the ROC curves to predict $F \geq$ $2, F \geq 3$ and $F=4$ were $0.893,0.908$ and 0.937 respectively [97]. A multicentre study from 2012 confirms ARFI as a good method for predicting cirrhosis in HCV patients [98]; however a problem area remains with stages F0-F1 where overlap of measurements persists.

In a pooled meta-analysis assessing the performance of ARFI in the staging of liver fibrosis due to $\mathrm{HCV}, \mathrm{HBV}$ and $\mathrm{NASH}$, patient data were available from eight studies 
including 518 patients, all with biopsy as a reference method. The mean diagnostic accuracy of ARFI expressed as area under the ROC curve was 0.87 for the diagnosis of significant fibrosis $(F \geq 2), 0.91$ for the diagnosis of severe fibrosis $(F \geq 3)$ and 0.93 for the diagnosis of cirrhosis [99]. However there have been differences in the areas under the ROC curves for HCV vs. HBV with 0.88 vs. 0.79 for $F \geq 2,0.90$ vs. 0.83 for $F \geq 3$ and 0.92 vs. 0.90 for $F=4$, respectively. In a further metaanalysis addressing the efficiency of ARFI for the staging of liver fibrosis, 36 studies including 3,951 patients were included. The mean diagnostic accuracy of ARFI expressed as area under the ROC curve was 0.84 for the diagnosis of significant fibrosis $(F \geq 2), 0.89$ for the diagnosis of severe fibrosis $(F \geq 3)$ and 0.91 for the diagnosis of liver cirrhosis $(F=4)$ [100].

A number of studies have compared the diagnostic performance of ARFI with TE. In a cohort of 139 consecutive patients with chronic HCV, ARFI has been shown to be more accurate than TE for both significant and more severe stages of fibrosis [101]. In prior studies, for the prediction of severe fibrosis, ARFI and TE appear to have the same diagnostic performance [96, 102, 103]. In the prediction of $F \geq 1$ or $F \geq 2$, however, TE outperformed ARFI in two studies [102, 103], while ARFI and TE were equal for all $\mathrm{F}$ stages [96]. In a recent prospective study of 321 consecutive patients undergoing assessment with ARFI, TE with the Fibroscan M- and XLprobes, and liver biopsy within 1 month after elastography, ARFI was shown to be reliable in the assessment of liver fibrosis, especially in nonobese patients [104]. In this study, ARFI had a measurement failure rate of $0 \%$, compared to $2.3 \%$ and $11.2 \%$ for the XL and M probes of Fibroscan respectively. The M probe slightly outperformed ARFI in the diagnosis of moderate fibrosis with areas under the ROC curves of 0.81 and 0.88 .

Data on the influence of different confounding factors on ARFI measurements are limited. Liver stiffness is affected by both physiological and pathological processes. Like TE, ARFI values are influenced by acute inflammation $[105,106]$. While TE is affected by both moderate and high aminotransferase levels, ARFI appears to be affected by high levels as shown in a large multicentre study [106]. It has been shown that food intake significantly increases ARFI values [107] and measurements should therefore be performed in a fasting state. While initially validated for $\mathrm{HCV}$, there is growing evidence that ARFI is accurate in predicting NAFLD fibrosis. Significant correlation between ARFI values and the degree of fibrosis has been shown [108, 109]. More recently, ARFI has been investigated as a discriminating method between NASH and simple steatosis $[110,111]$. Significantly higher ARFI velocities in NASH, and areas under the ROC curves of $0.87-0.9$ for the differentiation between NASH and simple steatosis were found.

In conclusion, ARFI is easy to perform with good reproducibility. The technology is incorporated in conventional ultrasound systems, and results are available within seconds. This method has been shown to have good diagnostic accuracy for the staging of fibrosis grades $F \geq 2$ and $F \geq 3$ and excellent diagnostic accuracy for $F=4$. Drawbacks are a small pre-determined measurement area, and validation is not as extensive as for TE as yet.

\section{Two-dimensional shear wave elastography}

The shear wave elastography (SWE) Aixplorer ${ }^{\mathrm{TM}}$ ultrasound system (SuperSonic Imagine S.A, Aix-en-Provence, France) generates shear waves in tissue from the acoustic radiation force obtained with focussed ultrasound pulses. Hard- and software are proprietary [68]. Serial pulses create plane shear waves that propagate transversely. Plane wave imaging is used to determine the speed of shear waves. Tissue elasticity is related to shear wave velocity and expressed in $\mathrm{kPa}$. It allows the generation of a quasi real-time two-dimensional map of tissue elasticity, which is superimposed in colour on B-mode images at a low frame rate of approximately $1 / \mathrm{s}$. As in most SE systems, the range of colours is from red (soft tissue) to blue (hard tissue). On a frozen image, mean and standard deviation of tissue stiffness can be displayed within a set ROI (Fig. 10). A potential advantage of 2D-SWE real-time information on shear wave speed is the display and measurement in a two-dimensional area as opposed to a point or line fashion as ARFI or TE does. Only a few studies have been reported to date. In a study limited to 121 patients with $\mathrm{HCV}$, SWE was superior to TE in the detection of $F>2$ [112]. In a further study limited to 113 patients with $\mathrm{HCV}$, SWE achieved areas under the ROC curves of $0.95,0.96$ and 0.97 for the prediction of $F \geq 2, F \geq 3$ and $F=4$, respectively, comparing favourably to TE where areas under the ROC curves of 0.85 , 0.86 and 0.94 were achieved for the prediction of $F \geq 2, F \geq 3$ and $F=4$, respectively [113]. In a study comparing the performance of SWE to that of TE (M and XL probes), the applicability of SWE in patients with ascites was $86 \%$ ( $55 \%$ for TE) [114]. Although these initial results are promising, more studies are necessary to validate the technique for other aetiologies, in other centres and for other factors that may influence measurements such as steatosis and inflammation.

\section{Strain elastography (real-time tissue elastography)}

Strain elastography is technically distinct from transient elastography, using a conventional ultrasound transducer to collect signals with and without distortion of tissue. This distortion is achieved by way of external compression, which may be applied free hand, with the US transducer, or by endogenous movements (arterial pulsation or cardiac motion). While initially used for the assessment of focal lesions in the pancreas, prostate, breast and thyroid, this method is now also being used for liver fibrosis. 
Fig. 10 Example of grade F3 fibrosis as shown on shear wave elastography (SWE), a quasi realtime two-dimensional map of tissue elasticity superimposed in colour on B-mode images

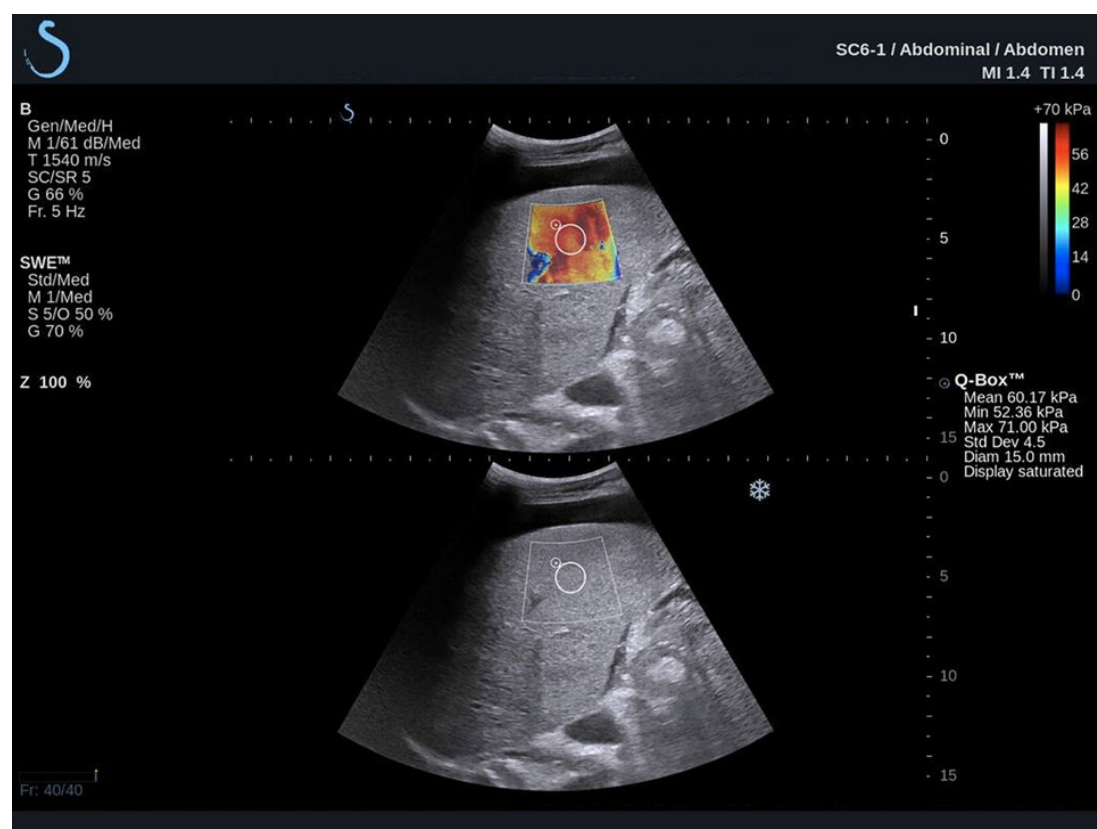

B-mode ultrasound is used to select the area of liver to the sampled. A colour map is then laid over the B-mode image in real time - hence the term real-time elastography, representing areas of different tissue deformabilities, which in turn are related to stiffness. Strain elastography is designed to provide a qualitative measurement of stiffness. In most systems the display conventionally ranges from red (soft tissue) to blue (hard tissue). SE is the only elastographic technique that works in real time at up to 20 frames/s and on a large field of view. Attempts at semi-quantitative interpretation have been made using scoring systems, e.g. by encoding the colour map and assigning values, e.g. between blue $=0$ and red $=255$ [115], or histogram analysis [116]. Another approach is the use of a specifically designed software for quantification of the colour map output [117], achieving area under the ROC curve values of 0.75 for the diagnosis of $F \geq 2,0.73$ for the diagnosis of severe $F \geq 3$ and 0.69 for the diagnosis of cirrhosis. Studies have predominantly involved patients with chronic HCV [115, 117-120], but also NASH fibrosis and cirrhosis [121]. The optimal approach of quantifying strain elastography, as well as standardisation of the stressor modality are yet to be determined. A recommendation for clinical use in the liver awaits more evidence and validation.

\section{Conclusion}

Conventional B-mode ultrasound remains a valuable tool in first-line screening of patients with chronic liver disease, supplemented by portal venous Doppler studies. While elastographic methods of TE and ARFI have now been validated for the assessment of fibrosis, other elastographic technologies are emerging and are likely to become more widely applied.

\section{Future perspective}

The increasing prevalence of chronic liver disease, including fatty liver disease, together with the need to minimise invasive liver biopsies will continue to provide substantial drive for ultrasound research and development.

\section{Conventional B-mode ultrasound}

- Quantification of echointensity in the diagnosis of fatty liver disease is an area of recent interest. Standardisation of technique and interobserver reproducibility will need to be addressed.

- Quantitative and semi-quantitative assessment of echotexture in the diagnosis of fibrosis and fatty liver disease is being developed

\section{Doppler ultrasound}

- The role of Doppler ultrasound in chronic liver disease is likely to remain principally in the diagnosis of portal venous hypertension

\section{Contrast-enhanced ultrasound}

- Kupffer-phase contrast agents can be used in the grading of fibrosis as well as in the detection of focal lesions, and it is hoped that these agents will become more widely available. 


\section{Elastography}

- More widespread use of the two most extensively validated and established techniques of TE and ARFI is expected, and further shear wave elastography techniques are likely to become more widely adopted and evaluated

\section{Financial disclosures None declared.}

Open Access This article is distributed under the terms of the Creative Commons Attribution License which permits any use, distribution, and reproduction in any medium, provided the original author(s) and the source are credited.

\section{References}

1. Williams CD, Stengel J, Asike MI et al (2011) Prevalence of nonalcoholic fatty liver disease and nonalcoholic steatohepatitis among a largely middle-aged population utilizing ultrasound and liver biopsy: a prospective study. Gastroenterology 140(1):124-131

2. Younossi ZM, Stepanova M, Afendy M et al (2011) Changes in the prevalence of the most common causes of chronic liver diseases in the United States from 1988 to 2008. Clin Gastroenterol Hepatol 9(6):524-530, e521; quiz e560

3. Ludwig J, Viggiano TR, McGill DB, Oh BJ (1980) Nonalcoholic steatohepatitis: Mayo Clinic experiences with a hitherto unnamed disease. Mayo Clin Proc 55(7):434-438

4. Bedossa P, Bioulac-Sage P, Callard P, Chevallier M, Degott C, Deugnier $Y$ et al (1994) Intraobserver and interobserver variations in liver biopsy interpretation in patients with chronic hepatitis C. The French METAVIR Cooperative Study Group. Hepatology 20(1 Pt 1): $15-20$

5. Brunt EM, Janney CG, Di Bisceglie AM, Neuschwander-Tetri BA, Bacon BR (1999) Nonalcoholic steatohepatitis: a proposal for grading and staging the histological lesions. Am J Gastroenterol 94(9): 2467-2474

6. Kleiner DE, Brunt EM, Van Natta M et al (2005) Design and validation of a histological scoring system for nonalcoholic fatty liver disease. Hepatology 41(6):1313-1321

7. Dixon JB, Bhathal PS, Hughes NR, O'Brien PE (2004) Nonalcoholic fatty liver disease: Improvement in liver histological analysis with weight loss. Hepatology 39(6):1647-1654

8. McHutchison J, Poynard T, Afdhal N (2006) Fibrosis as an end point for clinical trials in liver disease: a report of the international fibrosis group. Clin Gastroenterol Hepatol 4(10):1214-1220

9. Gebo KA, Herlong HF, Torbenson MS et al (2002) Role of liver biopsy in management of chronic hepatitis $\mathrm{C}$ : a systematic review. Hepatology 36(5 Suppl 1):S161-S172

10. Seeff LB, Everson GT, Morgan TR et al (2010) Complication rate of percutaneous liver biopsies among persons with advanced chronic liver disease in the HALT-C trial. Clin Gastroenterol Hepatol 8(10): 877-883

11. Piccinino F, Sagnelli E, Pasquale G, Giusti G (1986) Complications following percutaneous liver biopsy. A multicentre retrospective study on 68,276 biopsies. J Hepatol 2(2):165-173

12. Cadranel JF, Rufat P, Degos F (2000) Practices of liver biopsy in France: results of a prospective nationwide survey. For the Group of Epidemiology of the French Association for the Study of the Liver (AFEF). Hepatology 32(3):477-481

13. Lee RG (1994) Diagnostic liver pathology. Mosby, St. Louis
14. Regev A, Berho M, Jeffers LJ et al (2002) Sampling error and intraobserver variation in liver biopsy in patients with chronic HCV infection. Am J Gastroenterol 97(10):2614-2618

15. Mottin CC, Moretto M, Padoin AV et al (2004) The role of ultrasound in the diagnosis of hepatic steatosis in morbidly obese patients. Obes Surg 14(5):635-637

16. Bohte AE, van Werven JR, Bipat S, Stoker J (2011) The diagnostic accuracy of US, CT, MRI and 1H-MRS for the evaluation of hepatic steatosis compared with liver biopsy: a meta-analysis. Eur Radiol 21(1):87-97

17. El-Koofy N, El-Karaksy H, El-Akel W et al (2012) Ultrasonography as a non-invasive tool for detection of nonalcoholic fatty liver disease in overweight/obese Egyptian children. Eur J Radiol 81(11):3120-3123

18. Bohte AE, Koot BG, van der Baan-Slootweg OH et al (2012) US cannot be used to predict the presence or severity of hepatic steatosis in severely obese adolescents. Radiology 262(1):327-334

19. Strauss S, Gavish E, Gottlieb P, Katsnelson L (2007) Interobserver and intraobserver variability in the sonographic assessment of fatty liver. AJR Am J Roentgenol 189(6):W320-W323

20. Webb M, Yeshua H, Zelber-Sagi S et al (2009) Diagnostic value of a computerized hepatorenal index for sonographic quantification of liver steatosis. AJR Am J Roentgenol 192(4):909-914

21. Marshall RH, Eissa M, Bluth EI, Gulotta PM, Davis NK (2012) Hepatorenal index as an accurate, simple, and effective tool in screening for steatosis. AJR Am J Roentgenol 199(5):997-1002

22. Borges VF, Diniz AL, Cotrim HP, Rocha HL, Andrade NB (2013) Sonographic hepatorenal ratio: a noninvasive method to diagnose nonalcoholic steatosis. J Clin Ultrasound 41(1):18-25

23. Martin-Rodriguez JL, Arrebola JP, Jimenez-Moleon JJ, Olea N, Gonzalez-Calvin JL (2014) Sonographic quantification of a hepato-renal index for the assessment of hepatic steatosis in comparison with $3 \mathrm{~T}$ proton magnetic resonance spectroscopy. Eur $\mathrm{J}$ Gastroenterol Hepatol 26(1):88-94

24. Lee CH, Kim KA, Lee J et al (2011) Fade-out sign on hepatic tissue harmonic compound sonography: a value as a new sign in the diagnosis of fatty liver. Eur J Radiol 80(3):e258-e262

25. Oktar SO, Yucel C, Ozdemir H, Uluturk A, Isik S (2003) Comparison of conventional sonography, real-time compound sonography, tissue harmonic sonography, and tissue harmonic compound sonography of abdominal and pelvic lesions. AJR Am J Roentgenol 181(5):1341-1347

26. Ortega D, Burns PN, Hope Simpson D, Wilson SR (2001) Tissue harmonic imaging: is it a benefit for bile duct sonography? AJR Am J Roentgenol 176(3):653-659

27. Tranquart F, Grenier N, Eder V, Pourcelot L (1999) Clinical use of ultrasound tissue harmonic imaging. Ultrasound Med Biol 25(6): 889-894

28. Toyoda H, Kumada T, Kamiyama N et al (2009) B-mode ultrasound with algorithm based on statistical analysis of signals: evaluation of liver fibrosis in patients with chronic hepatitis C. AJR Am J Roentgenol 193(4):1037-1043

29. Ricci P, Marigliano C, Cantisani V et al (2013) Ultrasound evaluation of liver fibrosis: preliminary experience with acoustic structure quantification (ASQ) software. Radiol Med 118(6):995-1010

30. Kuroda H, Kakisaka K, Kamiyama N et al (2012) Non-invasive determination of hepatic steatosis by acoustic structure quantification from ultrasound echo amplitude. World J Gastroenterol 18(29):3889 3895

31. Choong CC, Venkatesh SK, Siew EP (2012) Accuracy of routine clinical ultrasound for staging of liver fibrosis. J Clin Imaging Sci 2:58

32. Nishiura $T$, Watanabe $H$, Ito $M$ et al (2005) Ultrasound evaluation of the fibrosis stage in chronic liver disease by the simultaneous use of low and high frequency probes. Br J Radiol 78(927):189-197 
33. Di Lelio A, Cestari C, Lomazzi A, Beretta L (1989) Cirrhosis: diagnosis with sonographic study of the liver surface. Radiology 172(2):389-392

34. Filly RA, Reddy SG, Nalbandian AB, Lu Y, Callen PW (2002) Sonographic evaluation of liver nodularity: Inspection of deep versus superficial surfaces of the liver. J Clin Ultrasound 30(7): 399-407

35. Colli A, Fraquelli M, Andreoletti M, Marino B, Zuccoli E, Conte D (2003) Severe liver fibrosis or cirrhosis: accuracy of US for detection-analysis of 300 cases. Radiology 227(1):89-94

36. Vessal S, Naidoo S, Hodson J, Stella DL, Gibson RN (2009) Hepatic vein morphology: a new sonographic diagnostic parameter in the investigation of cirrhosis? J Ultrasound Med 28(9): $1219-1227$

37. Gibson RN (2011) Ultrasound evaluation of hepatic vein morphology: a promising simple diagnostic tool? Imaging Med 3(2):3

38. Allan RB, Thoirs KA (2014) A comparison of liver surface and hepatic vein wall ultrasound as markers for fibrosis or cirrhosis of the liver. Radiography 20(1):8-14

39. Bellamy EA, Bossi MC, Cosgrove DO (1984) Ultrasound demonstration of changes in the normal portal venous system following a meal. Br J Radiol 57(674):147-149

40. Gaiani S, Bolondi L, Li Bassi S, Santi V, Zironi G, Barbara L (1989) Effect of meal on portal hemodynamics in healthy humans and in patients with chronic liver disease. Hepatology 9(6):815-819

41. Weinreb J, Kumari S, Phillips G, Pochaczevsky R (1982) Portal vein measurements by real-time sonography. AJR Am J Roentgenol 139(3):497-499

42. Bolondi L, Gandolfi L, Arienti Vet al (1982) Ultrasonography in the diagnosis of portal hypertension: diminished response of portal vessels to respiration. Radiology 142(1):167-172

43. Vilgrain V, Lebrec D, Menu Y, Scherrer A, Nahum H (1990) Comparison between ultrasonographic signs and the degree of portal hypertension in patients with cirrhosis. Gastrointest Radiol 15(3):218-222

44. Lafortune M, Marleau D, Breton G, Viallet A, Lavoie P, Huet PM (1984) Portal venous system measurements in portal hypertension. Radiology 151(1):27-30

45. Bolondi L, Mazziotti A, Arienti V et al (1984) Ultrasonographic study of portal venous system in portal hypertension and after portosystemic shunt operations. Surgery 95(3):261-269

46. Lim AK, Patel N, Eckersley RJ et al (2005) Can Doppler sonography grade the severity of hepatitis C-related liver disease? AJR Am J Roentgenol 184(6):1848-1853

47. Sudhamshu KC, Sharma D, Chataut SP (2011) Hepatic vein waveforms in liver cirrhosis re-evaluated. Hepatol Int 5(1):581-585

48. Gibson PR, Gibson RN, Donlan JD, Ditchfield MR, Bhathal PS (1991) Duplex Doppler ultrasound of the ligamentum teres and portal vein: a clinically useful adjunct in the evaluation of patients with known or suspected chronic liver disease or portal hypertension. J Gastroenterol Hepatol 6(1):61-65

49. Ditchfield MR, Gibson RN, Donlan JD, Gibson PR (1992) Duplex Doppler ultrasound signs of portal hypertension: relative diagnostic value of examination of paraumbilical vein, portal vein and spleen. Australas Radiol 36(2):102-105

50. Zoli M, Marchesini G, Cordiani MR et al (1986) Echo-Doppler measurement of splanchnic blood flow in control and cirrhotic subjects. J Clin Ultrasound 14(6):429-435

51. Moriyasu F, Nishida O, Ban N et al (1986) "Congestion index" of the portal vein. AJR Am J Roentgenol 146(4):735-739

52. Gaiani S, Bolondi L, Li Bassi S, Zironi G, Siringo S, Barbara L (1991) Prevalence of spontaneous hepatofugal portal flow in liver cirrhosis. Clinical and endoscopic correlation in 228 patients. Gastroenterology 100(1):160-167

53. von Herbay A, Frieling T, Haussinger D (2000) Color Doppler sonographic evaluation of spontaneous portosystemic shunts and inversion of portal venous flow in patients with cirrhosis. J Clin Ultrasound 28(7):332-339

54. Li FH, Hao J, Xia JG, Li HL, Fang H (2005) Hemodynamic analysis of esophageal varices in patients with liver cirrhosis using color Doppler ultrasound. World J Gastroenterol 11(29):4560-4565

55. Wachsberg RH, Simmons MZ (1994) Coronary vein diameter and flow direction in patients with portal hypertension: evaluation with duplex sonography and correlation with variceal bleeding. AJR Am J Roentgenol 162(3):637-641

56. Adithan S, Venkatesan B, Sundarajan E, Kate V, Kalayarasan R (2010) Color Doppler evaluation of left gastric vein hemodynamics in cirrhosis with portal hypertension and its correlation with esophageal varices and variceal bleed. Indian J Radiol Imaging 20(4): 289-293

57. Piscaglia F, Bolondi L (2006) The safety of Sonovue in abdominal applications: retrospective analysis of 23188 investigations. Ultrasound Med Biol 32(9):1369-1375

58. Albrecht T, Blomley MJ, Cosgrove DO et al (1999) Non-invasive diagnosis of hepatic cirrhosis by transit-time analysis of an ultrasound contrast agent. Lancet 353(9164):1579-1583

59. Blomley MJ, Lim AK, Harvey CJ et al (2003) Liver microbubble transit time compared with histology and Child-Pugh score in diffuse liver disease: a cross sectional study. Gut 52(8):1188-1193

60. Ridolfi F, Abbattista T, Busilacchi P, Brunelli E (2012) Contrastenhanced ultrasound evaluation of hepatic microvascular changes in liver diseases. World J Gastroenterol 18(37):5225-5230

61. Lim AK, Taylor-Robinson SD, Patel N et al (2005) Hepatic vein transit times using a microbubble agent can predict disease severity non-invasively in patients with hepatitis C. Gut 54(1):128-133

62. Lim AK, Patel N, Eckersley RJ et al (2010) Hepatic vein transit times of a microbubble agent in assessing response to antiviral treatment in patients with chronic hepatitis C. J Viral Hepat 17(11):778-783

63. Lim AK, Patel N, Eckersley RJ et al (2006) Hepatic vein transit time of SonoVue: a comparative study with Levovist. Radiology 240(1): $130-135$

64. Ishibashi H, Maruyama H, Takahashi M et al (2012) Demonstration of intrahepatic accumulated microbubble on ultrasound represents the grade of hepatic fibrosis. Eur Radiol 22(5):1083-1090

65. Kudo M, Hatanaka K, Maekawa K (2010) Newly developed novel ultrasound technique, defect reperfusion ultrasound imaging, using sonazoid in the management of hepatocellular carcinoma. Oncology 78(Suppl 1):40-45

66. Frulio N, Trillaud H (2013) Ultrasound elastography in liver. Diagn Interv Imaging 94(5):515-534

67. Shiina T (2013) JSUM ultrasound elastography practice guidelines: basics and terminology. J Med Ultrason 40:309-323

68. Bamber J, Cosgrove D, Dietrich CF et al (2013) EFSUMB guidelines and recommendations on the clinical use of ultrasound elastography. Part 1: basic principles and technology. Ultraschall Med 34(2):169-184

69. Song ZZ (2008) Acute viral hepatitis increases liver stiffness values measured by transient elastography. Hepatology 48(1):349-350, author reply 350

70. Cobbold JF, Taylor-Robinson SD (2008) Transient elastography in acute hepatitis: all that's stiff is not fibrosis. Hepatology $47(2)$ : 370-372

71. Coco B, Oliveri F, Maina AM et al (2007) Transient elastography: a new surrogate marker of liver fibrosis influenced by major changes of transaminases. J Viral Hepat 14(5):360-369

72. Millonig G, Reimann FM, Friedrich S et al (2008) Extrahepatic cholestasis increases liver stiffness (FibroScan) irrespective of fibrosis. Hepatology 48(5):1718-1723

73. Millonig G, Friedrich S, Adolf $S$ et al (2010) Liver stiffness is directly influenced by central venous pressure. J Hepatol 52(2): 206-210 
74. Reiberger T, Ferlitsch A, Payer BA, Pinter M, Homoncik M, PeckRadosavljevic M (2012) Non-selective beta-blockers improve the correlation of liver stiffness and portal pressure in advanced cirrhosis. J Gastroenterol 47(5):561-568

75. Mederacke I, Wursthorn K, Kirschner J et al (2009) Food intake increases liver stiffness in patients with chronic or resolved hepatitis C virus infection. Liver Int 29(10):1500-1506

76. Castera L, Foucher J, Bernard PH et al (2010) Pitfalls of liver stiffness measurement: a 5-year prospective study of 13,369 examinations. Hepatology 51(3):828-835

77. Myers RP, Pomier-Layrargues G, Kirsch R et al (2012) Feasibility and diagnostic performance of the FibroScan XL probe for liver stiffness measurement in overweight and obese patients. Hepatology 55(1):199-208

78. Engelmann G, Gebhardt C, Wenning D et al (2012) Feasibility study and control values of transient elastography in healthy children. Eur J Pediatr 171(2):353-360

79. Ziol M, Handra-Luca A, Kettaneh A et al (2005) Noninvasive assessment of liver fibrosis by measurement of stiffness in patients with chronic hepatitis C. Hepatology 41(1):48-54

80. de Ledinghen V, Douvin C, Kettaneh A et al (2006) Diagnosis of hepatic fibrosis and cirrhosis by transient elastography in HIV/ hepatitis C virus-coinfected patients. J Acquir Immune Defic Syndr 41(2): 175-179

81. Vergara S, Macias J, Rivero A et al (2007) The use of transient elastometry for assessing liver fibrosis in patients with HIV and hepatitis C virus coinfection. Clin Infect Dis 45(8):969-974

82. Marcellin P, Ziol M, Bedossa P et al (2009) Non-invasive assessment of liver fibrosis by stiffness measurement in patients with chronic hepatitis B. Liver Int 29(2):242-247

83. Wong VW, Vergniol J, Wong GL et al (2010) Diagnosis of fibrosis and cirrhosis using liver stiffness measurement in nonalcoholic fatty liver disease. Hepatology 51(2):454-462

84. Nahon P, Kettaneh A, Tengher-Barna I et al (2008) Assessment of liver fibrosis using transient elastography in patients with alcoholic liver disease. J Hepatol 49(6):1062-1068

85. Tsochatzis EA, Gurusamy KS, Ntaoula S, Cholongitas E, Davidson BR, Burroughs AK (2011) Elastography for the diagnosis of severity of fibrosis in chronic liver disease: a meta-analysis of diagnostic accuracy. J Hepatol 54(4):650-659

86. Chon YE, Choi EH, Song KJ et al (2012) Performance of transient elastography for the staging of liver fibrosis in patients with chronic hepatitis B: a meta-analysis. PLoS One 7(9):e44930

87. Sasso M, Beaugrand M, de Ledinghen V et al (2010) Controlled attenuation parameter (CAP): a novel VCTE guided ultrasonic attenuation measurement for the evaluation of hepatic steatosis: preliminary study and validation in a cohort of patients with chronic liver disease from various causes. Ultrasound Med Biol 36(11): $1825-1835$

88. de Ledinghen V, Vergniol J, Foucher J, Merrouche W, le Bail B (2012) Non-invasive diagnosis of liver steatosis using controlled attenuation parameter (CAP) and transient elastography. Liver Int 32(6):911-918

89. Myers RP, Pollett A, Kirsch R et al (2012) Controlled Attenuation Parameter (CAP): a noninvasive method for the detection of hepatic steatosis based on transient elastography. Liver Int 32(6):902-910

90. Kumar M, Rastogi A, Singh T et al (2013) Controlled attenuation parameter for non-invasive assessment of hepatic steatosis: does etiology affect performance? J Gastroenterol Hepatol 28(7):11941201

91. de Ledinghen V, Vergniol J, Capdepont $\mathrm{M}$ et al (2013) Controlled attenuation parameter (CAP) for the diagnosis of steatosis: a prospective study of 5323 examinations. J Hepatol. doi:10.1016/j.jhep. 2013.12.018
92. Jaffer OS, Lung PF, Bosanac D et al (2012) Acoustic radiation force impulse quantification: repeatability of measurements in selected liver segments and influence of age, body mass index and liver capsule-to-box distance. Br J Radiol 85(1018):e858-e863

93. Piscaglia F, Salvatore V, Di Donato R et al (2011) Accuracy of VirtualTouch Acoustic Radiation Force Impulse (ARFI) imaging for the diagnosis of cirrhosis during liver ultrasonography. Ultraschall Med 32(2):167-175

94. Bota S, Sporea I, Sirli R, Popescu A, Danila M, Sendroiu M (2011) Factors that influence the correlation of acoustic radiation force impulse (ARFI), elastography with liver fibrosis. Med Ultrason 13(2):135-140

95. Bota S, Sporea I, Sirli R, Popescu A, Danila M, Costachescu D (2012) Intra- and interoperator reproducibility of acoustic radiation force impulse (ARFI) elastography-preliminary results. Ultrasound Med Biol 38(7):1103-1108

96. Friedrich-Rust M, Wunder K, Kriener S et al (2009) Liver fibrosis in viral hepatitis: noninvasive assessment with acoustic radiation force impulse imaging versus transient elastography. Radiology 252(2): 595-604

97. Sporea I, Sirli R, Bota S et al (2011) Is ARFI elastography reliable for predicting fibrosis severity in chronic HCV hepatitis? World J Radiol 3(7): 188-193

98. Sporea I, Bota S, Peck-Radosavljevic M et al (2012) Acoustic Radiation Force Impulse elastography for fibrosis evaluation in patients with chronic hepatitis $\mathrm{C}$ : an international multicenter study. Eur J Radiol 81(12):4112-4118

99. Friedrich-Rust M, Nierhoff J, Lupsor M et al (2012) Performance of Acoustic Radiation Force Impulse imaging for the staging of liver fibrosis: a pooled meta-analysis. J Viral Hepat 19(2):e212-e219

100. Nierhoff J, Chavez Ortiz AA, Herrmann E, Zeuzem S, FriedrichRust M (2013) The efficiency of acoustic radiation force impulse imaging for the staging of liver fibrosis: a meta-analysis. Eur Radiol. doi:10.1007/s00330-013-2927-6

101. Rizzo L, Calvaruso V, Cacopardo B et al (2011) Comparison of transient elastography and acoustic radiation force impulse for noninvasive staging of liver fibrosis in patients with chronic hepatitis $\mathrm{C}$. Am J Gastroenterol 106(12):2112-2120

102. Sporea I, Sirli RL, Deleanu A et al (2011) Acoustic radiation force impulse elastography as compared to transient elastography and liver biopsy in patients with chronic hepatopathies. Ultraschall Med 32(Suppl 1):S46-S52

103. Lupsor M, Badea R, Stefanescu H et al (2009) Performance of a new elastographic method (ARFI technology) compared to unidimensional transient elastography in the noninvasive assessment of chronic hepatitis C. Preliminary results. J Gastrointest Liver Dis 18(3):303-310

104. Cassinotto C, Lapuyade B, Ait-Ali A et al (2013) Liver fibrosis: noninvasive assessment with acoustic radiation force impulse elastography-comparison with FibroScan $\mathrm{M}$ and XL probes and FibroTest in patients with chronic liver disease. Radiology. doi:10. 1148/radiol.13122208

105. Yoon KT, Lim SM, Park JY et al (2012) Liver stiffness measurement using acoustic radiation force impulse (ARFI) elastography and effect of necroinflammation. Dig Dis Sci 57(6):1682-1691

106. Bota S, Sporea I, Peck-Radosavljevic M et al (2013) The influence of aminotransferase levels on liver stiffness assessed by acoustic radiation force impulse elastography: a retrospective multicentre study. Dig Liver Dis. doi:10.1016/j.dld.2013.02.008

107. Popescu A, Bota S, Sporea I et al (2013) The influence of food intake on liver stiffness values assessed by acoustic radiation force impulse elastography-preliminary results. Ultrasound Med Biol 39(4):579-584

108. Yoneda M, Suzuki K, Kato S et al (2010) Nonalcoholic fatty liver disease: US-based acoustic radiation force impulse elastography. Radiology 256(2):640-647 
109. Palmeri ML, Wang MH, Rouze NC et al (2011) Noninvasive evaluation of hepatic fibrosis using acoustic radiation force-based shear stiffness in patients with nonalcoholic fatty liver disease. $\mathrm{J}$ Hepatol 55(3):666-672

110. Fierbinteanu Braticevici C, Sporea I, Panaitescu E, Tribus L (2013) Value of acoustic radiation force impulse imaging elastography for non-invasive evaluation of patients with nonalcoholic fatty liver disease. Ultrasound Med Biol. doi:10.1016/j.ultrasmedbio.2013. 04.019

111. Guzman-Aroca F, Frutos-Bernal MD, Bas A et al (2012) Detection of non-alcoholic steatohepatitis in patients with morbid obesity before bariatric surgery: preliminary evaluation with acoustic radiation force impulse imaging. Eur Radiol 22(11):2525-2532

112. Ferraioli G, Tinelli C, Dal Bello B, Zicchetti M, Filice G, Filice C (2012) Accuracy of real-time shear wave elastography for assessing liver fibrosis in chronic hepatitis C: a pilot study. Hepatology 56(6): 2125-2133

113. Bavu E, Gennisson JL, Couade $M$ et al (2011) Noninvasive in vivo liver fibrosis evaluation using supersonic shear imaging: a clinical study on 113 hepatitis C virus patients. Ultrasound Med Biol 37(9): 1361-1373

114. Poynard T, Munteanu M, Luckina E et al (2013) Liver fibrosis evaluation using real-time shear wave elastography: applicability and diagnostic performance using methods without a gold standard. J Hepatol 58(5):928-935

115. Tatsumi C, Kudo M, Ueshima K et al (2010) Non-invasive evaluation of hepatic fibrosis for type $\mathrm{C}$ chronic hepatitis. Intervirology 53(1):76-81

116. Saftoiu A, Gheonea DI, Ciurea T (2007) Hue histogram analysis of real-time elastography images for noninvasive assessment of liver fibrosis. AJR Am J Roentgenol 189(4):W232-W233

117. Friedrich-Rust M, Ong MF, Herrmann E et al (2007) Real-time elastography for noninvasive assessment of liver fibrosis in chronic viral hepatitis. AJR Am J Roentgenol 188(3):758-764

118. Morikawa H, Fukuda K, Kobayashi S et al (2011) Real-time tissue elastography as a tool for the noninvasive assessment of liver stiffness in patients with chronic hepatitis C. J Gastroenterol 46(3): 350-358

119. Yada N, Kudo M, Morikawa H, Fujimoto K, Kato M, Kawada N (2013) Assessment of liver fibrosis with real-time tissue elastography in chronic viral hepatitis. Oncology 84(Suppl 1):13-20

120. Okada K, Matsumura T, Mitake T (2005) Development of real-time tissue elastography. Nihon Hoshasen Gijutsu Gakkai Zasshi 61(6): $811-816$

121. Orlacchio A, Bolacchi F, Antonicoli M et al (2012) Liver elasticity in NASH patients evaluated with real-time elastography (RTE). Ultrasound Med Biol 38(4):537-544 